\title{
SISTEM MONITORING ALARM DAN KENDALI JARAK JAUH POMPA TANGKI LIMBAH RADIOAKTIF CAIR BERBASIS SMS
}

\author{
Bisma Barron Patrianesha ${ }^{1,2}$, Ajat Sudrajat ${ }^{1}$, Fitria Hidayanti ${ }^{\mathrm{T}}$, Hari Suryanto ${ }^{2}$ \\ Teknik Fisika - Universitas Nasional, Jakarta \\ ${ }^{2} \mathrm{PRR}$ - BATAN \\ E-mail: bisma_barron@yahoo.com
}

\begin{abstract}
ABSTRAK
SISTEM MONITORING ALARM DAN KENDALI JARAK JAUH POMPA TANGKI LIMBAH RADIOAKTIF CAIR BERBASIS SMS. Tangki Limbah Radioaktif Cair di Pusat Radioisotop dan Radiofarmaka (PRR) - BATAN memerlukan sistem level alarm yang terkoneksi dengan peralatan pribadi opcrator agar potensi banjir akibat meluapnya Tungki Limbah Cair dapat dihindart. Salah satu fitur yang dewasa ini dapat digunakan adalah SMS. Tidak hanya level alarm yang digunakan untuk melakukan monitoring melalui SMS, tetapi pompa tangki juga dapat dikendalikan melalui SMS. Sensor yang đigunakan untuk mengukur level limbah radioaktif cair adalah Ultrasonic rangefinder, data level tersebut diakuisisi oleh mikrokontroler dengan setting alarm level tertentu. Alarm tersebut melalui RMC akan mengirimkan SMS ke operator. Selanjutnya pompa akin dioperasikan secara otomatis atau operator juga dapat melakukan kendali pompa dengan mengirimkan SMS ke RMC.
\end{abstract}

Kata kunci: Monitoring, alarm kendali, tangki limbah, mikrokontroler, SMS

\section{ABSTRACT}

SMS BASED ALARM MONITORING SYSTEM AND REMOTE CONTROL OF RADIOACTIVE LIQUID WASTE TANK PUMP. Radioactive Liquid Waste Tank in Centre for Radioisotopes and Radiopharmaceuticals - BATAN require level alarm system which is connected with personal equipment operator so that the ponential for Rooding due to overflowing Liguid Tank Waste can be ovoided. One of the features that can be zused widay is SMS, Not only the level of alarm that is used to monitor via SMS, but the pump tank ear also be controlled through SMS. Sensors are used to measure the level of liquid radioactive naste is Ultrasonic rangefinder, the level of data acquired by a microcontroller with a certain level alarm setting. The alarm throngh the RMC will send SMS to the operator. Furthermore, the pump will be operated automatically or operator can also control the pump by sending SMS to the RMC.

Keyword: Monitoring, Control, Waste Tank, Microcontroler, SMS

\section{PENDAHULUAN}

Pusat Radioisotop dan Radiofarmaka (PRR) - BATAN merupakan salah satu pusat di lingkungan Badan Tenaga Nuklit Nasional yang mempunyai tugas melaksanakan pendayagunaan dan pengembangan Teknologi Produksi Radioisotop dan Radiofarmaka. Untuk menunjang tugas pokok PRR tersebut diperlukan sebuah sistem keselamatan yang handal. Pengelolaan sistem keselamatan tersebut dilakukan oleh Bidang Keselamatan yang salah satu tugas dan fungsi bidang keselamatan adalah melakukan pengelolaan limbah radioaktif,

Limbah radioaktif eair di PRR berupa cairan yang berasal dari hasil kegiatan pendayagunaan dan pengembangan yang sudah tidak memiliki nilai guna lagi. Tidak hanya itu limbah radioaktif juga dapat berasal dari air hujan yang ditampung sebagai sampel untuk mengetahui apakah ada lepasan zat radioaktif ke udara.

Limbah radioaktif tersebut ditampung ke dalam tangki bawah tanah dengan volume 
wrang lebih 20.000 liter, dengan kapasitas iersebut bila terjadi kelalaian proses yang tidak Jiketahui dan hujan yang terus menerus akan Lapat menyebabkan banjir akibat meluapnya arghi limbah cair. Meluapnya tarngki limbah air radioaktif melalui saluran input yang ada 5lantat ini, dapat membahayakan hagi pekerja juga peralatan yang ada di Fasilitas dioisotop dan Radiofarmaka.

Pengawasan keselamatan termasuk ggawasan tangki limbah radioaktif cair akukan secara rutin setiap hari kerja, Namun luar hari kerja tidak ada pekerja yang -akukan pengawasan, Oleb karena itu, erlukan suatu sistem yang dapat mengetahui - Jian tertentu dan melakukan aksi terhadap dian itu tanpa langsung datang ke termpat sdian. Salah satunya dengan menggunakan cm yang mengirimkan SMS (Short ange Service) berupa teks ketika suatu - vilai tertentu terjadi, dan secura otomatis - melakukan aksi penanggulanganrya Ce dapat diperintah juga melalui sms. Selain andapat juga bebcrapa system notifikasi Sahan yang dapat menginformasikan ke - tertentu mengenai kejadian tersebut. eri notifikasi dari lampu LED dan Buzzer. Scbagai contoh bila terjadi barjio'luapan lumbah cair, secara langsung dapat wi dan dapat dengan cepar direspon agar terjadi kerngian-kerugian terhadap Laja dan peralatan yang ada di fasilitas ssebut.

\section{DASAR TEORI}

\section{A. Review Sistem Monitoring Terkini}

Sudah hanyak perangkat yang dibust untuk menunjang syslem monitoring dan kontrol berbasis SMS dengan layanan GSM, din banyak juga bidang yang telah menerapkan aplikasi tersebut. Aplikasi yang menggunakan Telepon Seluler sebagai antarmuka transmitternya juga telah banyak dikembangkan. Kelemahan penggunaan handphone ini adalah terletak pada ketahanan handphone terhadap panas karena pada subu tertentu bandphone akan mati. Oleh karena itu, akan lebih baik jika digunakan GSM modem sebagai antarmukanya.

GSM modem tidak dapat metrangkap perubahan output sensor secara langsung. melainkan harus diolah menggunakan mikroprosesor atau mikrokontroler terlebih dahulu. Dan untuk melakukan konfigurasi sistemi cukup rumit. Penggunaan modul RMC iRemote Monitoring Controller) sangat memudahkan operator untuk melakukan konfigurasinya. Selain itu. RMC juga tidak membutuhkan software tambahan untuk melakukan konfigurasi. Kelebihan lain pada RMC ini adalah konfigurasi juga dapat dilakukan melalui SMS dengan format tertentu. Oleh karena itu. RMC dapat berfungsi secara Stand Alone.

Seiring derigan perkembangan teknlogi yang semakin eanggith. Basis redudansi notifikasi alert system monitoring juga bertambah tidak hanya menggunakan SMS tetapi bisa diketahui lewat e-mail ataupun mungkin aplikasi telepon selular lainnya. Namun notifikasi alert pada lokasi kritis juga perlus ditambah seperti dengan menambahkan buzzer dan LED (local) ke pos pengamanan sehingga bila terjadi kegagalan sinyal GSM, notifikasi alert tetap bisa tersampaikan.

\section{Sensor Ultrasonik}

Sensor ultrasonik adalah sensor yang bekerja berdasarkan prinsip pantulan gelombang suara. Frekuensi kerja sensor ultrasonik ini ada pada daerali di atas gelombang suara yaitu dari $40 \mathrm{KHz}$ hingga $400 \mathrm{KHz}$. Sensor ultrasonik terdiri dari dua unit, yaitu unit pemancar dan unit penerima.

Sensor ultrasonik ini mampu bekerja dengan menggunakan bidang pantul berupa benda padat atau pun benda cair. Berdasarkan pengujian dengan menggunakan pemantulast benda padat data yang didapatkan cukup linear dan untuk pengujian dengan kompensasi suhu, data yang didapatkan menjadi kurang bagus ${ }^{[001}$.

Pengujian dengan menggunakan bidang pantul berupa cairan didapatkan data yang cukup bagus karena selisih antara pembacaan sensor dengan jarak sebenarnya tidak turpaut terlalu jauh. Serla berdasar pada pengujian lersebut untuk penggunaan Pipa PVC sebagai metode untuk mengurangi riak dapat dilakukan tampa menimbulkan error yang tinggi $[$ ?

\section{Remote Monitoring Controller (RMC)}

Message Master 4000 (MM4000) adalah sebuah perangkat yang berdiri sendiri yang dibangun mengqunakan sebuah mikrokontroler 32 bit. Selain itu MM4000 digabungkan dengan modem GSM dual band serta rangkaian elektronik seperti Power Supply switching, input digital dengan sistem optik, output relay. 
indikator dan lain-lain. Internet Protokol (IP) merupakan basis dari RMC. dengan menggunakan antarmuka wveb user yang mudah digunakan.

Unit monitoring dan kendali merupakan unit monitoring sekaligus sebagai unit kendali dengan metode sms sebagai basisnya. Pada saat input berubah status dari normal menjadi alarm maka sms akan tcrkirim ke telepon genggam personel terksit,

Dalam modul tersebut terdapat software yang berfungsi untuk melakukan konfigurasi sistem monitoring dan sistem kendali. Dalam konfigurasinya dimungkinkan untuk melakukan pengaturan mengenai status input, status output, pengaturan alarm, pengaturan kelompok telepon, dan pengaturan sms ${ }^{\left[{ }^{[}\right]}$.

Pada perancangan yang dilakukan oleh Wayan Widiana pada tahun 2009, pembuatan perangkat keras belum dilakukan, dan berbeda dengan penelitian ini yang sudah melakukan realisasi.

\section{B. Rancang Bangun Sistem}

alur sebagai berikut:

Sistem yang akan dibangun mengikuti Bila melewati ketinggian limbah tertentu RMC akan menerima sinyal dari mikrokontroler kemudian secara otomatis mengirimkan SMS alarm ke operator dan mengaktifkan pompa. Setelah melakukan pembuangan, pompa tersebut dinon-aktifkan kembali secara otomatis. Serupa dengan cara aktifnya pompa, RMC akan menerima sinyal dari mikrokontroler bila sudah melewati batas minimum ketinggian dan secara otomatis akan mengirimkan SMS yang menyatakan bahwa ketinggian minimum telah terlewati, dan pompa akan non-aktif (mati) Gambaran umum sistem dapat dilihat pada gambar 1 .

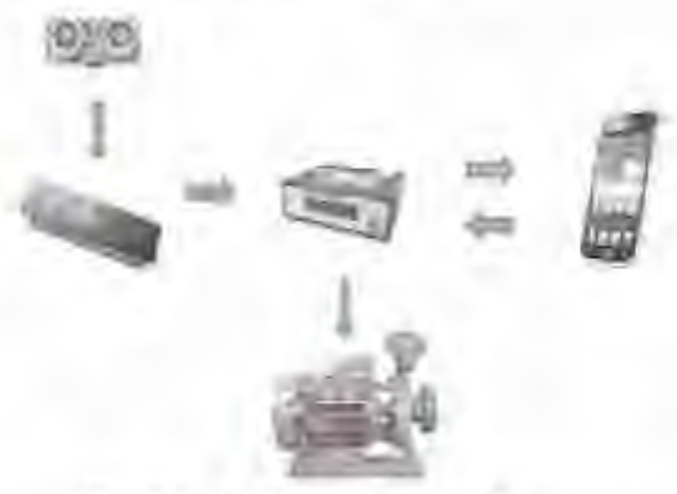

Gambar 1. Blok Diagram Sistem

\section{Perangkat Pengukur Ketinggian}

Perangkat ini tersusun atas Sensor Ultrasonic dan Sistem Minimum Mikrokontroler, Dalam pembuatannya sensor Ultrasonic ditempatkan di ujung atas sebuah pipa PVC berdiameter 6 inchi. Penggunaan pipa PVC ini dimaksudkan untuk mengurangi kemungkinan adanya riakan limbah cair radioaktif.

Sistem Minimum Mikrokontroler ditempatkan di sebuah panel bersama deugan power supply, LCD, Buzzer dan Lampu LED. Power Supply yang digunakan adalah $12 \mathrm{Vdc}$ kernudian diubah menjadi 5 Vdc menggunakan IC7805 sebagai daya untuk mengaktifkan panel. LCD display digunakan untuk menampilkan ketinggian aktual setiap detik sebingga bila terjadi perubahan signifikan dapat dilihat dengan lebih tepat, Sementara Buzzer akan mengeluarkan suara saat set Alarm terjadi pada suatu ketinggian tertentu, yaitu pada batas level atas dan batas level bawah.

Mikrokontroler untuk bekerja perlu menggunakan komponen elektronika dasar seperti kapasitor $20 \mathrm{pF}$ dan XTAL berfrekuensi $11.059200 \mathrm{~Hz}$. Keduanya digunakan sebagai sumber detak. Untuk bekerja sesuai dengan keinginan, mikrokontroler perlu di program dengan menggunakan Bahasa Pemrograman tertentu. Bahass pemrograman yang dipilih adalah BASCOM-AVR. Pemrograman yang telah dibuat perlu diunduh ke mikrokontroler dengan menggunakan DI-USB-AVR.

\section{Konfigurasi Remote Monitoring Controller (RMC)}

RMC (Remote Monitoring Controller) atau biasa disebut juga MM4000 merupakan perangkat yang digunakan untuk memonitor kejadian atau keadaan dari suatu kondisi yang diamati. Dalam hal ini yang diamati oleh RMC adalah level limbah radioaktif. Semua sinyal input dari mikrokontroler ataupun teks sms yang masuk diatut sedemikian rupa sehingga sistem uni berjalan sebagamana mestinya. 


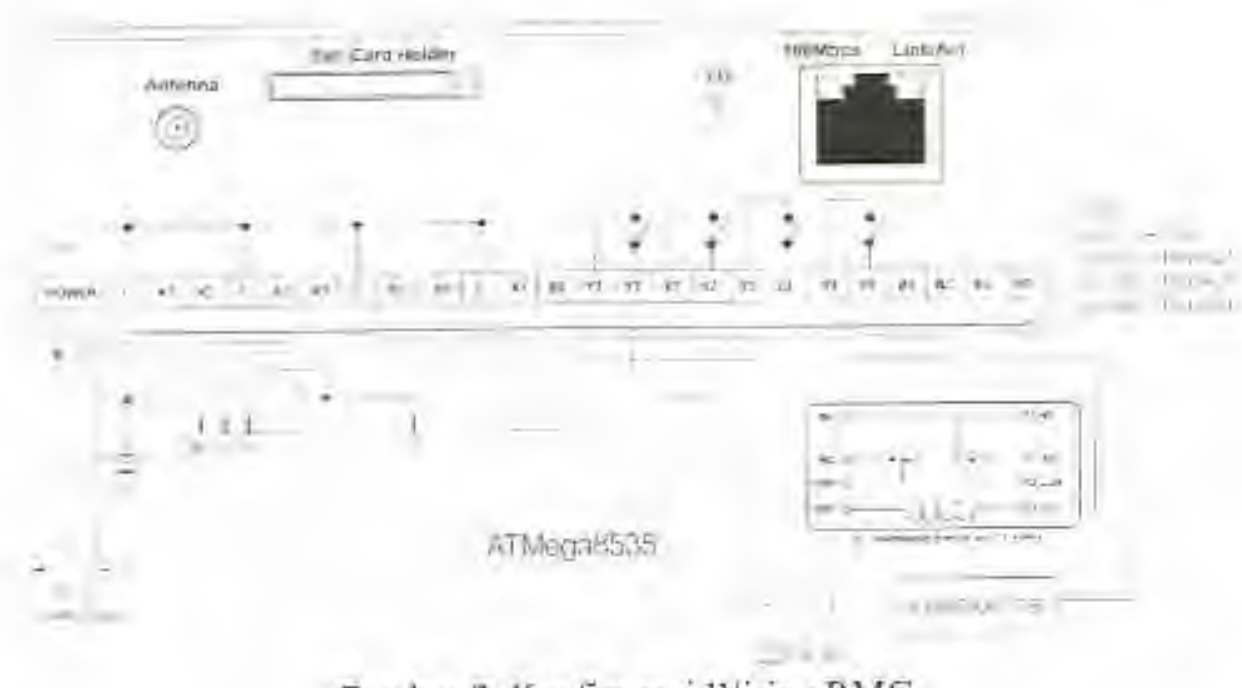

Gambar 2. Kontigurasi Wiring RMC

Pengabelan (wiring) dari RMC tunjukkan pada gambar 2. Input X1 \& X2 emibung dengan output Port A.0 dan Port L. Output Y1 terhubung dengan Relay $12 \mathrm{~V}$ atuk mengaktifkan pompa 3 fasa.

Internet Protokol (IP) merupakan basis ari RMC, dengan menggunakan antarmuka reh user yang mudah digunakan. Pengaturan sarbasis web memudahkan pengguna untuk nelakukan perubahan-perubahan sesuai tengan konfigurasi yang diinginkan.

Adapun konfigurasi berbasis web yang fliakukan adalah sebagai berikut:

Input X1 = Batas atas Alarm

Input X2 - Batas bawah Alarm

Output $Y 1=$ Pompa 3 fasa

Operator $1=085692234688$

Operator $2=085813673911$

Operator $3=08562892622$

Forward Number $=08889710930$

Escalation Group $=08889710930$

Authorized Group $=085692234688$

Logic Expression $=\mathrm{X} 1 \mid(\mathrm{Y} 1 \&$ \& $\mathrm{X} 2)$

AutoHealth Check $=$ Enable $(9.00 \mathrm{am})$

Internal Buzzer $=$ Enable $(10 \mathrm{~s})$

\section{Redundant Alert System}

Adapun peranigkat yang dipasang bagai pengganti SMS ketika permasalahan mis muncul, adalah dengan membuat Indikator ari LED yang dipasang di pos pengamanan ang dijaga setiap waktu. Ketika sinyal hilang talam waktu yang cukup lama, dan saat itu crjadi Alarm, maka LED akan menyala sbagai informasi kepada pos pengamanan suliwa batas atas limbah radioaktif cair telah terlewati. Selain itu terdapat Buzzer saat kondisi kehilangan sinyal terjadi sehingga informasi keadaan tetap disampaikan.

\section{HASIL DAN PEMBAHASAN}

\section{A. Deskripsi Unjuk Kerja Sistem}

Saat dihidupkan, Instrumen pengukur akan secara terus menerus menginformasikan secara local tentang ketinggian limbah radioaktif cair. Sampai suatu saat batas atas dari ketinggian terlampaui, maka mikrokontroler akan memberikan sinyal 'low' ke pin XI RMC dan kemudian pompa akan diaktifkan untuk melakukan pengosongan limbah radioaktif cair serta RMC juga akan mengirimkan SMS ke operator. Pengosongan ini akan berlangsung sampai ada sinyal "low" dari mikrokontroler di pin X2 RMC. Ketika hal ini terjadi maka pompa akan dinonaktifkan dan RMC akan mengirimkan SMS berisi informasi bahwa ketinggian limbah sudah berada di batas bawah.

Selain itu bila terjadi sesuatu pada perangkat pengukur sehingga menyebabkan perangkat pengukur tidak mengirimkan sinyal yang sebenarnya, maka pompa secara semiotomatis dapat diaktifkan dengan cara operator mengirimkan SMS berisi "Hon pompat" dan untuk menonaktifkan pompa operator dapat mengirimkan SMS berisi "Hoff pompal"

Terkait dengan izin pengiriman limbah, maka saat pengujian system pompa tidak diaktifkan tetapi diganti dengan Indikator yang terdiri dari 3 buah lampu bohlam yang masing-masing lampu mewakili tiap Line listrik R-S-T. 

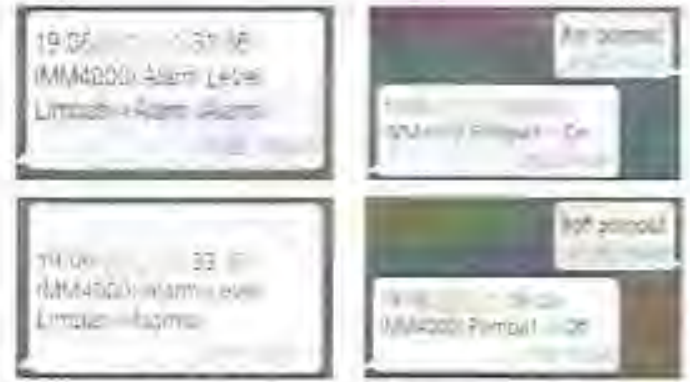

Gambar 3. Notifikasi Informasi dan Kendali Semi Otomatis melalui SMS

\section{B. Pengujian Sensor Ultrasonik}

Pengujian ini bertujuan untuk mengetahui hubungan antara cacahan dari mikrokontroler dengan jarak aktual. Cara pengambilan data uji ini adalah dengan menghadapkan sensor dengan benda padat. Kemudian jarak diantara kedua benda tersebut diubah-ubah.

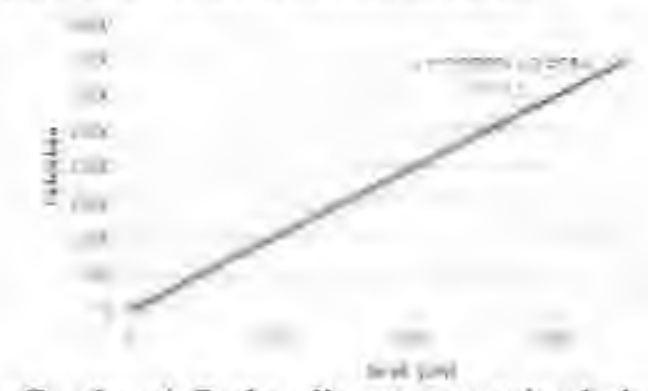

Gambar 4, Perbandingan antara jarak dengan Cacahan

Data eacahan akan tampil di LCD kemudian data tersebut dibandingkan dengan jarak actual. Pada penerapannya data cacahan tersebut diolah oleh mikrokontroler sehingga data yang keluar dari LCD berupa data ketinggian limbah cair radioaktif.

Pada Gambar 4 ditunjukkan grafik Hubungan antara Jarak dengan Jumlah Cacahan. Dapat dilihat bahwa grafik tersebut menghasilkan garis dengan $\mathrm{R}^{2}=1$ yang artinya data $X$ (Jarak) dan data $Y$ (Cacahan) mempunyai korelasi linier yang sempurna.

\section{Tingkat Keberhasilan Sistem dan Waktu Respon}

Keberhasilan sistem dalam melakukan 10 kali task, dapat dikatakan berhasil $100 \%$. Satu kali task dimulai dari pembacaan sensor, pengaktifar pompa sampai penon-aktifan pompa. Selama pengujian ini, peralatan memang berada dalam kondisi baik, dan tidak ada gangguan-gangguan yang mungkin saja terjadi. Oleh karena itu. Task tersebut dapat dilakukan dengan baik oleh sistem.

\begin{tabular}{|c|c|c|}
\hline No & $\begin{array}{l}\text { Task } \\
\text { ke- }\end{array}$ & Status \\
\hline I & 1 & Berhasil \\
\hline 2 & 2 & Berhasil \\
\hline 3 & 3 & Berhasil \\
\hline 4 & 4 & Berhasil \\
\hline 5 & 5 & Berhasil \\
\hline 6 & 6 & Berhasil \\
\hline 7 & 7 & Berhasil \\
\hline 8 & 8 & Berhasil \\
\hline 9 & 9 & Berhasil \\
\hline 10 & 10 & Berhasil \\
\hline
\end{tabular}

Pada tabel 2 dapat dilihat data waktu respon RMC untuk mengaktifkan pompa dan mengirimkan SMS sampai diterima oleh operator. Semua waktu untuk merespon dari RMC selalu berada di atas 20 detik. HaI ini terjadi karena dalam setiap Output Mikrokontroler PortA.0 dan PortA.1 yang masuk ke RMC harus dipastikan apakah sebagai input Alarm atau bukan. Ketika output dari mikrokontroler mengeluarkan logika 'low" tapi tidak selama 20 detik, maka RMC mengatakan sinyal tersebut bukan input Alarm. Namun ketika mikrokontroler terus menerus mengeluarkan logika 'low' dan mempertahankan keadaan tersebut minimal selama 20 detik, maka dapat dipastikan input itu adalah Alarm dan RMC segera melakukan tindakan untuk mengaktifkan pompa dan mengirimkan SMS kepada Operator.

Tabel 2. Waktu Respon terhadap Alarm

\begin{tabular}{clcc}
\hline No & Kondisi & Pompa & Operator I \\
\hline 1 & Alarm & 20 & 26 \\
2 & Normal & 20 & 27 \\
3 & Alarm & 20 & 31 \\
4 & Normal & 20 & 29 \\
5 & Alarm & 20 & 31 \\
6 & Normal & 20 & 23 \\
7 & Alarm & 20 & 27 \\
8 & Normal & 20 & 24 \\
9 & Alarm & 20 & 30 \\
10 & Normal & 20 & 30 \\
11 & Alarm & 20 & 32 \\
12 & Normal & 20 & 28 \\
13 & Alarm & 20 & 27 \\
14 & Normal & 20 & 28 \\
\hline \multicolumn{2}{c}{ Rata-rata } & 20 & 28.07 \\
\hline
\end{tabular}


Untuk mengaktifkan pompa, waktu yang diperlukan adalah 20 detik setelah Mikrokontroler pertama kali menyatakan Alarm Artinya ketika RMC menyatakan Output 'low' dari mikorokontroler adalah Alarm, maka RMC langsung mengaktifkan pompa dan disaat itu pula RMC mengirimkan SMS. Pada kolom keempat terdapat waktu proses pengiriman SMS setelah Alarm pertama kali dinyatakan oleh Mikrokontroler. Rata-rata waktu untuk mengirimkan SMS ke operator I adalah 28,07 dengan waktu terlama adalah 32 detik dan waktu tercepat adalah 32 detik.

Pada kenyataannya untuk menyampaikan informasi menggunakan SMS sangatlah bergantung pada kestabilan jaringan GSM dari provider yang digunakan. Signal Strength di daerah kawasan Nuklir Serpong cukup stabil terbukti bahwa selama pengujian system, rentang Signal Strength berada pada angka $37 \%-72 \%$.

\section{KESIMPULAN}

Dari hasil penjabaran di atas, bisa didapatkan beberapa kesimpulan sebagai berikut:

I. Telah berhasil dibuat perangkat pengukut ketinggian tangki limbah radioaktif cair dengan menggunakan sensor ultrasonik.

2. Rata-rata error dari pembacaan jarak menggunakan sensor ultrasonic adalah 1,9 $\mathrm{cm}$ dengan range pengukuran terbaik pada jarak $10-140 \mathrm{~cm}$.

3. Telah berhasil dibuat alat monitoring keadaan alam level limbah radioaktif cair dan dapat juga mengendalikan pompa dari jarak jauh berbasis SMS.

4. Respon untuk menghidupkan pompa pembuangan limbah radioaktif cukup cepat yaitu 20 detik setelah keadaan Alarm diketahui.

5. Melalui SMS, operator dapat mengetahui kejadian dengan cukup cepat yaitu dengan rata-rata waktu 28,07 detik.

6. Saat terjadi kegagalan sinyal GSM, system tetap dapat memberikan informasi Alarm melalui Lampu LED dan Buzzer kepada pihak yang terkait.

\section{DAFTAR PUSTAKA}

1. Ardiansyah, Ma'rifin dan Taufiqqurahman, "Sistem Informasi Bencana Banjir
(Akuisisi Data Multiple Sensor)" PENS ITS. Surabaya. (2011).

2. Balza. Ahmad, "Sistem Alarm Mobil Menggunakan Mikrokontroler AT89\$52 Berbasis SMS", Dalam Jurnal Telkommika, Vol 6 No. I hlm. 15-20. Yogyakarta, (2008).

3. Bernat, Herbin, "Perangkat Pengendali Beban Dari Jarak Jauh Dengan Aplikasì SMS menggunakan J2ME", Yogyakarta. (2012).

4. Hakim, Ahmad Rofiq, "Aplikasi Monitoring Suhu Ruangan Berbasis Komputer dan SMS Gateway", Dalam Jurnal Informatika Mulawarman, Vol 5 No.3 hlm. 32-38, Samarinda, (2010).

5. Istiyanto, Jazi Eko, "Rancangan Dan Implementasi Prototipe Sistem Kendali Jarak Jauh Berbasis AT89C52 Dan Layanan SMS GSM", Dalam Jurnal ILMU DASAR Vol 5 No.2 him. 76-87, Yogyakarta, (2004).

6. Kuhnel. Claus, BASCOM Programming of Micrucontrollers with Ease: An Introduction by Program Examples, USA: Universal Publishers/uPUBLISH.cont., (2010).

7. Sutrisno, Wahyu $\mathrm{Tri}_{+}$"Sensor PING Parallax Sebagai Pengukur Jarak pad Robot Cerdas Pemadam Api Berbasis Mikrokontroler ATMega8535", Surakarta, (2010).

8. Wahjono, Heru Dwi, "Sistem Manajemen Komunikasi Data Jarak Jauh Berbasis Teknologi SMS dan Radiotelemetry Untuk Pemantauan Kualitas Air", Dalam $J /$ Vol $4 \mathrm{No}_{1} 1 \mathrm{hlm}$. 88-96, Jakarta, (2008).

9. Widiana, 1 Wayan, "Perancangan Sistem dan Monitoring dan Kendali Jarak Jauh menggunakan SMS", Dalam Prosiding Seminai Nasional SDM Teknologi Nuklir VII - STTN, 16 November 2011 , hlm.377381., (2008).

10. Manual Message Master 4000 Remote Monitoring Controller User V 3.07. Available http://www picobox,biz, diakses Juni (2013). 